Check for updates

Cite this: RSC Adv., 2018, 8, 36959

\title{
Study on the blockage mechanism of carbon dioxide hydrate slurry and its microscopic particle characteristics
}

\begin{abstract}
Xiaofang LV, (D) *a Wenqing Li, ${ }^{\text {b }}$ Bohui Shi ${ }^{\text {(D) }}{ }^{\mathrm{c}}$ and Shidong Zhou ${ }^{\mathrm{a}}$
In order to better understand the process of carbon dioxide hydrate formation and blockage, a series of experiments were performed in a high pressure hydrate experimental loop which has been constructed. The impacts of varying flow rate, pressure, and restarting of the pump on the plugging have been studied in this paper. The particle chord length distribution in the process of hydrate formation and blockage was monitored in real time by using the advanced device, Focused Beam Reflectance Measurement (FBRM). The results showed that the time taken for hydrate blockage to occur would significantly decrease at higher pressure, which meant higher pressure promoted the occurrence of hydrate blockage. At the same time, the time needed for carbon dioxide hydrate blockage increased with the flow rate. That is, the time for hydrate blockage increased when the flow rate changed from $754 \mathrm{~kg} \mathrm{~h}^{-1}$ to $1657 \mathrm{~kg} \mathrm{~h}^{-1}$. And once the pipeline has been blocked, restarting the pump may make the problem more serious. In addition, particle agglomeration led to a significant change in the particle chord length distribution during the process of hydrate formation and blockage, and the hydrate particle coalescence was the key cause of the hydrate plugging.
\end{abstract}

Received 31st August 2018

Accepted 26th October 2018

DOI: $10.1039 / \mathrm{c} 8 \mathrm{ra07259k}$

rsc.li/rsc-advances is effectively based on the use of an environmentally-friendly secondary fluid whose role is to transport cold energy from the place of production (engine room) to places of use. ${ }^{19}$ Thus, secondary refrigeration makes it possible to limit the amount of primary refrigerant used and to confine it. In slurry systems, such as $\mathrm{CO}_{2}$ hydrate slurry, ${ }^{20}$ energy is stored during the phase change of the storage material dispersed in a carrier liquid (continuous phase). Phase change material (PCM) slurry has a higher energy density than single-phase secondary refrigerants due to both the sensible and latent heat capacities. One of the advantages of $\mathrm{CO}_{2}$ hydrate slurry is that mechanical processes such as scraped- or brushed-surface heat exchangers are not required to produce it, unlike ice slurry. It also forms at temperatures higher than $273 \mathrm{~K}$, which makes it suitable for airconditioning applications. ${ }^{21,22}$ But whatever the type of secondary refrigeration application, slurry flow properties are of paramount importance to assess the overall feasibility of the process. Previous studies performed have shown that $\mathrm{CO}_{2}$ hydrate slurry in the aqueous phase can agglomerate in a dynamic loop ${ }^{23-25}$ and even form plugs as in pipelines ${ }^{26}$ at a high hydrate fraction of $20 \mathrm{vol} \%$ (with a stirred tank reactor) or from a small hydrate fraction of 5-10 vol\%.

In addition, hydrate formation and blockage in pipelines has been a trouble for onshore and offshore petroleum production for a long time. ${ }^{27}$ Especially as offshore oil and gas production moves towards the deep water, the risk of plugging due to gas hydrate formation remains one of the most common flowassurance problems in deep-water subsea oil and gas 
operations. ${ }^{28}$ Due to the potentially severe economic impact of forming a gas hydrate plug, it is critical to understand gas hydrate formation and accumulation mechanisms in flowlines. Many researches have been published about the plug and blocking of natural gas hydrates in different flow system. ${ }^{29-34}$ However, few researches have been reported about the flow stability of $\mathrm{CO}_{2}$ hydrate slurry. Meanwhile, the flow characteristics of $\mathrm{CO}_{2}$ hydrates slurry are critical for being as a secondary two-phase refrigerant in refrigeration process to ensure a continuous cooling conveying, especially the rheological property. ${ }^{23-25}$ If blocking happens in the $\mathrm{CO}_{2}$ hydrate slurry, restart the system immediately would be a general solution for recovering the flow ability of the system. But in fact, what would occur after restart the blocking system is not known clearly. Moreover, the study about the influence factor of the $\mathrm{CO}_{2}$ hydrate blockage time is only on the stage of qualitative without quantitative realizations. For example: how much the blockage time will be reduced by the improvement of the pressure? How much the blockage time will be increased by the increase of the flow rate? Therefore, according to the above situation, this paper performed a series of experiments on hydrate blockage time in a water- $\mathrm{CO}_{2}$ system, studied the quantitative influence of the factor such as pressure, flow rate on the hydrate plugging time and represented the change of the particle size due to the particle aggregation in the process of blockage. Here, the $\mathrm{CO}_{2}-$ water system was used mainly based on the safety consideration, and it was also to compare with the natural gas hydrate blockage research to considerate the influence of the hydrate structure on the blockage experiment.

\section{Experimental apparatus and materials}

\subsection{High pressure hydrate experimental loop}

Experimental tests have been performed with the high pressure hydrate experimental loop devoted to Flow Assurance studies (Fig. 1). The loop, in which gas and liquid are separately injected by a plunger compressor and a custom-made magnetic centrifugal pump, is constituted of a test section. Two sight glasses are set in the test sections. The gas injection point is considered as the inlet of the test section. At the outlet of the test section, gas and liquid are collected in an insulated separator and re-directed to the test section towards the compressor and the pump. Several gas tanks allow maintenance of loop and/or separator pressure as hydrate is forming.

The test section is a stainless steel pipe, the internal diameter of which is $2.54 \mathrm{~cm}$ (1 inch) and the length $30 \mathrm{~m}$. Geometrically it is constituted of two rectilinear and horizontal parts, connectedly a circular one with a low curvature. It is connected to a separator. The test section is surrounded by a $5.08 \mathrm{~cm}$ (2 inches) diameter jacket in which a calorific water/ glycol blend circulates in counter-current. Process temperature can be controlled from -20 to $80{ }^{\circ} \mathrm{C}$.

This experimental flow loop is equipped with several sensors. Thermocouples are regularly set along the pipe, inside the separator, inside the water/glycol system and on the

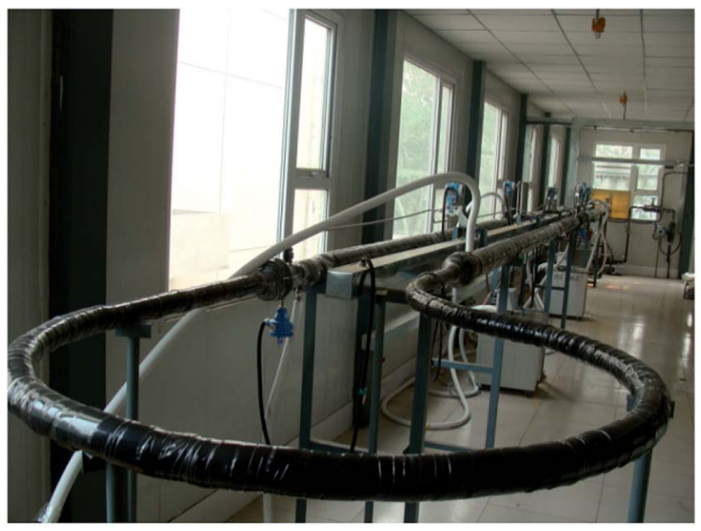

Fig. 1 The picture of high pressure hydrate experimental loop.

different gas utilities. A Coriolis flowmeter measures the density of the liquid mixture and the flow rate. The mean density of the multiphase fluid can also be measured using two FM1000 gamma ray densitometers. Differential pressure sensors are located along the loop to follow the evolution of the linear pressure drop along the loop. A rapid data acquisition is used and permits to detect rapid phenomena.

The evolution of objects (droplets, bubbles and solid particles) carried inside the flow can be followed thanks to a FBRM (Focused Beam Reflectance Measurements, Mettler-Toledo Lasentec ${ }^{\circledR}$ Product, Group-Lasentec ${ }^{\circledR}$ D600) probe which was recently installed on the loop. This apparatus comprises a low intensity rotating LASER beam (Fig. 2) which is reflected when intercepting a particle. From the reflection time a chord length is deduced. After every measurement duration which was chosen equal to $10 \mathrm{~s}$, a Chord Length Distribution (CLD) and a mean chord length are given. This CLD gives an idea of the Particle Size Distribution (PSD) of the objects carried by the flow. The lower and upper limits of the FBRM CLD are 0.5 and $1000 \mu \mathrm{m}$, respectively. The probe window of probe cuts the flow streamlines at an angle of $45^{\circ}$ and reaches the centre of the pipe. The RBRM probe was used to estimate the initial water droplet (Dp) size inside the fluid and to follow the hydrate particles agglomeration with the time. The mean squareweighted chord length can give more weight to the longer chord length and it is particularly well adapted to

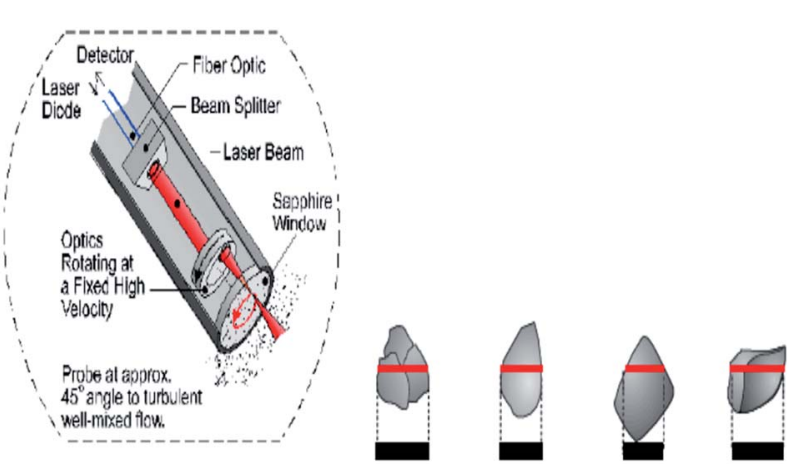

Fig. 2 Principle of the FBRM particle size analyzer. 
agglomeration phenomena. The mathematical expressions of the square-weighted mean chord lengths are given below:

$$
\bar{C}=\frac{\sum_{i=a}^{b} y_{i} M_{i}^{2} \times M_{i}}{\sum_{i=a}^{b} y_{i} M_{i}^{2}}
$$

With $M_{i}$ the center of the $i_{\text {th }}$ interval and $y_{i}$ the probability of measuring a chord included in the $i_{\text {th }}$ interval.

\subsection{Fluids}

To better simulate the practical situation, tap water and $\mathrm{CO}_{2}$ (purity 99\%)-which are known as the formation materials of the structure I hydrate-were adopted as the test fluids in the experiments. Preliminary Chen-Guo model ${ }^{9}$ permitted to determine the curve of hydrate formation (Fig. 3) of the defined natural gas composition.

\subsection{Procedure of the experiments}

(1) The entire experimental loop is vacuumed until the vacuum degree reaches 0.09 $\mathrm{MPa}$.

(2) Load the tap water of $85 \mathrm{~L}$ into the separator, and turn on the magnetic pump to circulate the tap water fluid at constant flow rate (such as: $754 \mathrm{~kg} \mathrm{~h}^{-1}, 1041 \mathrm{~kg} \mathrm{~h}^{-1}, 1375 \mathrm{~kg} \mathrm{~h}^{-1}, 1657 \mathrm{~kg}$ $\left.\mathrm{h}^{-1}\right)$.

(3) Open the temperature control device, and set the experimental initial temperature $\left(T_{0}\right)$ of the water bath system as around $20^{\circ} \mathrm{C}$.

(4) When the loop temperature reaches to $T_{0}$, and start the data acquisition system. At the same time, turn on the Focused Beam Reflectance Measurements to monitor the chord length distribution in fluid until the average chord length of fluid fluctuates in $\pm 0.2 \mu \mathrm{m}$.

(5) Through pressure reducing valve, gas is injected into the separator until the pressure reaches the setting experimental pressure $P$ (2.8 and $3.8 \mathrm{MPa}$ in this paper). The setting value of

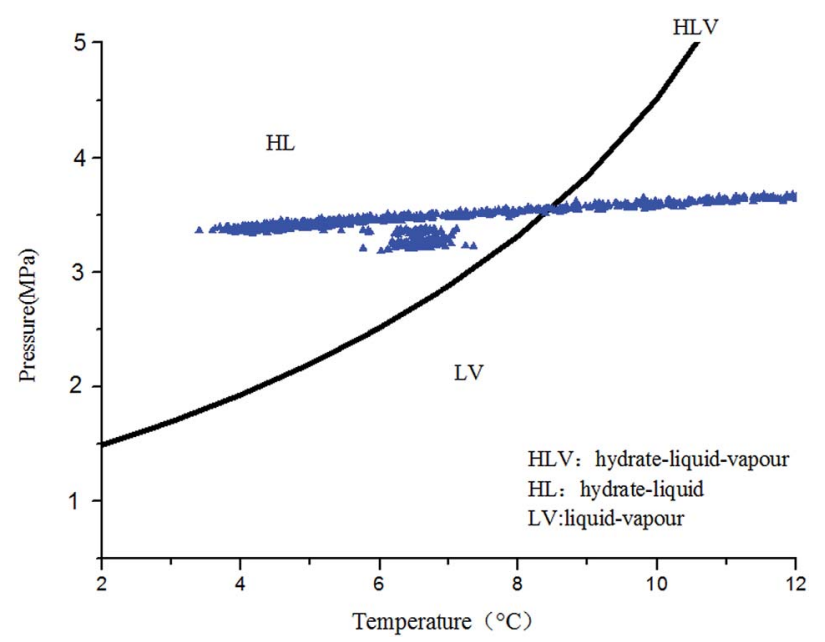

Fig. 3 Hydrate formation curve of $\mathrm{CO}_{2}$. the temperature control device is lowered to the experimental final target temperature $T_{\mathrm{c}}$ (for example: $2{ }^{\circ} \mathrm{C}$ ), so that to cool down the loop as well as the fluids.

(6) When a set of the experiment of hydrate formation is finished, the setting value of the temperature control device is turned up again, from $T_{\mathrm{c}}$ to $T_{0}$. Repeat steps (1-4) for the next set after hydrate dissociation. Each group experiment lasts about 3-6 hours.

\section{Results and discussion}

\subsection{The blockage mechanism of $\mathrm{CO}_{2}$ hydrate plugging and effect of restarting}

Through the experimental observation from the sight glass in our loop, the block process of water $+\mathrm{CO}_{2}$ system could be divided into four periods, as shown in Fig. 4a-d. (a) Water in the pipe wall section reacted with $\mathrm{CO}_{2}$ firstly and generated a thin layer of hydrate. (b) The water near the hydrate layer continued to react with the dissolved $\mathrm{CO}_{2}$ and the hydrate continuously adhered to the hydrate layer. The hydrate layer was getting thicker gradually and finally blocked the pipe. ${ }^{30}$ (c) When the pump restarted, the fluid could wash away the hydrate stemming. Some hydrates were washed away, while some might accumulate at the back of the blockage and increase the contact area. (d) Hydrate formed near the increscent contact area and adhered on it continuously, and finally blocked the pipe again. After restarting of the pump made the flow rate resume again, the recovery of flow rate would continue to drop down to zero, and a second blockage happened. Furthermore, it can no longer make the fluid flow again after the second hydrate blockage by raising the pump frequency. That means that the secondary restarting of the pump can lead to a serious hydrate blockage accident. $^{28}$

\subsection{The influence of the flow rate on the blockage of hydrate}

The paper changed the initial flow rate of the system $(15 \mathrm{~Hz} / 754$ $\mathrm{kg} \mathrm{h}{ }^{-1}, 20 \mathrm{~Hz} / 1041 \mathrm{~kg} \mathrm{~h}{ }^{-1}, 25 \mathrm{~Hz} / 1375 \mathrm{~kg} \mathrm{~h} \mathrm{~h}^{-1}, 30 \mathrm{~Hz} / 1657 \mathrm{~kg}$ $\mathrm{h}^{-1}$ ) to study its effects on the formation, blockage temperature and blockage time of carbon dioxide hydrate under the same conditions,as shown in Fig. 5-8. According to the above four graphs, the system with different flow rates began to plug at 3.5 $\mathrm{MPa}$, and the corresponding $\mathrm{CO}_{2}$ hydrate formation temperature was about $8.4{ }^{\circ} \mathrm{C}$ (Fig. 3) under this pressure. It was found that the flow rate nearly remained unchanged before the formation of hydrate, but quickly dropped to zero when hydrate begins to form in large quantities, then plugged the flow loop. At the same time, the temperature at which hydrate begins to form in large quantities keeps increased with the increased flow rate, which was shown in Fig. 9. Due to the shortage of heat transfer time for flowing medium under large flow rate condition, cooling efficiency was weakened, the subcooling degree decreased, which further resulted in decreasing in the driving force hydrate formation rate, ultimately caused an increase in the plugging time. On the other hand, the larger flow rate increased the gas-liquid contacting area and the number of nucleation sites, enhancing mass transfer between liquid and 


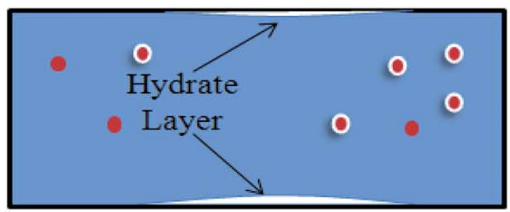

(a)
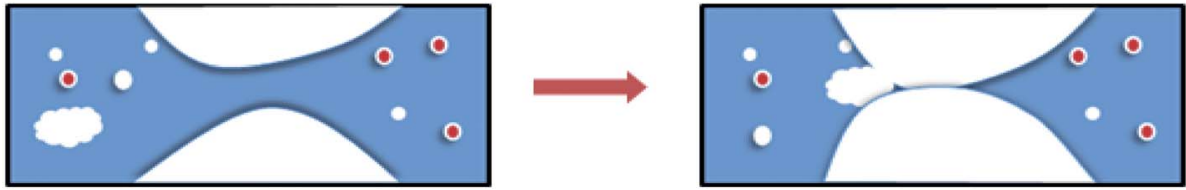

(b)
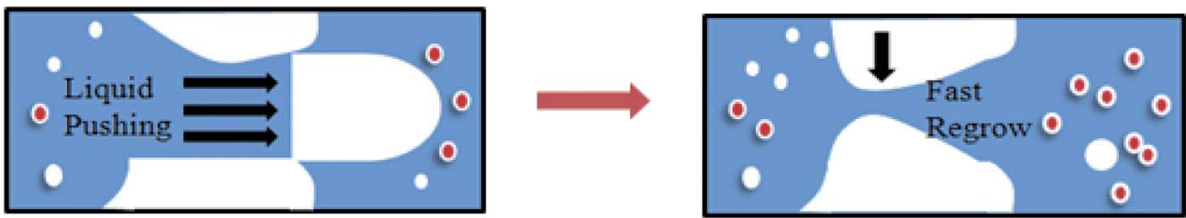

(c)

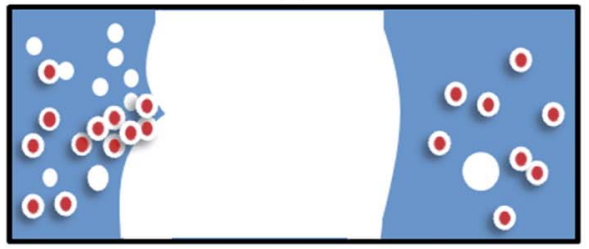

(d)

Fig. 4 Procedures of blockage by $\mathrm{CO}_{2}$ hydrates formation in the loop $(\mathrm{a}-\mathrm{d})$.

gas, which helped the formation of hydrate. However, the stronger shear action could delay or inhibit the formation rate of nucleation sites on gas-liquid contacting surface, made it difficult to meet the critical dimensions for hydrate formation, thus extended the induction period. At the same time, the larger flow rate had stronger entrainment and shear ability, reduced the coalescence and deposition of hydrate particles, made it difficult to block the loop, which caused an increase of the plugging time.

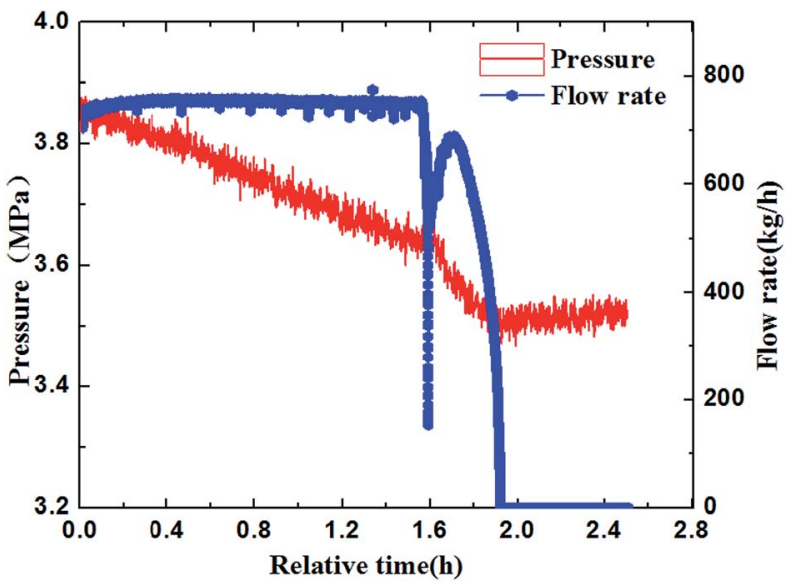

Fig. 5 Flow rate as a function of relative time $\left(15 \mathrm{~Hz} / 754 \mathrm{~kg} \mathrm{~h}^{-1}\right)$.
It could be concluded from Fig. 5-8 that under certain pressure and relatively low flow rate $(15 \mathrm{~Hz} / 20 \mathrm{~Hz})$, the time from the beginning of hydrate formation in large quantities to the blockage of the pipeline was nearly the same (approximately $0.25 \mathrm{~h}$ ), and the plugging time was short, while this time was longer under high flow rate (about $1.17 \mathrm{~h}$ ). Therefore, it might exist a critical flow rate in the process of hydrate blockage, below which the plugging time was relatively short. ${ }^{35}$ The curve

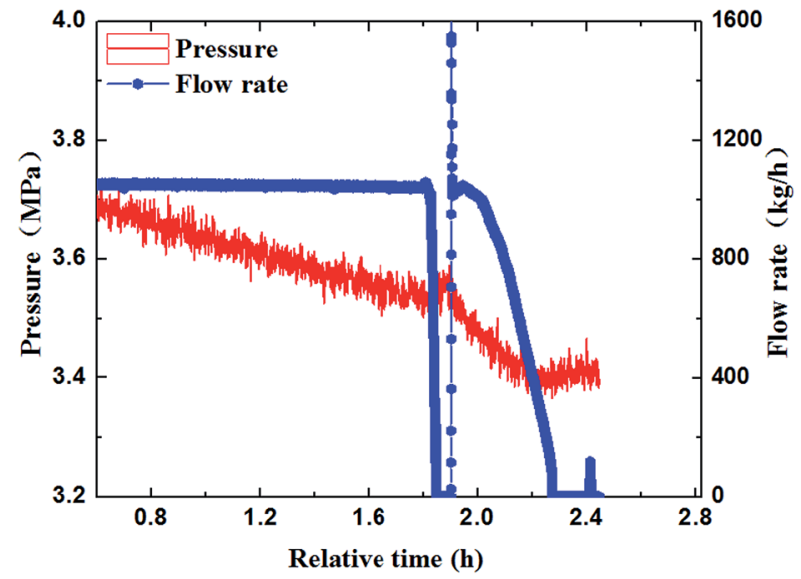

Fig. 6 Flow rate as a function of relative time $\left(20 \mathrm{~Hz} / 1041 \mathrm{~kg} \mathrm{~h}^{-1}\right)$. 


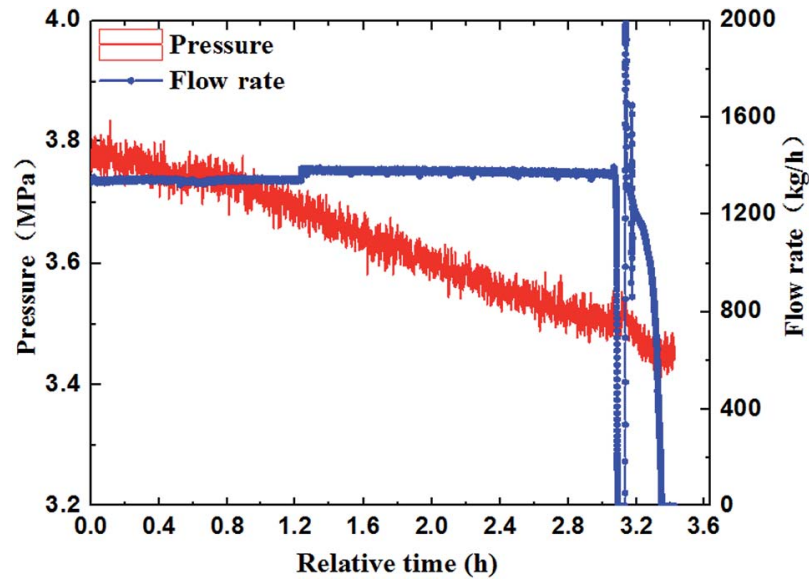

Fig. 7 Flow rate as a function of relative time $\left(25 \mathrm{~Hz} / 1375 \mathrm{~kg} \mathrm{~h}^{-1}\right)$.

of the temperature when hydrate begins to form in large quantities and plugging time with the variation of flow rate was shown in Fig. 10. It could be concluded that the temperature mentioned above and the plugging time increased with the

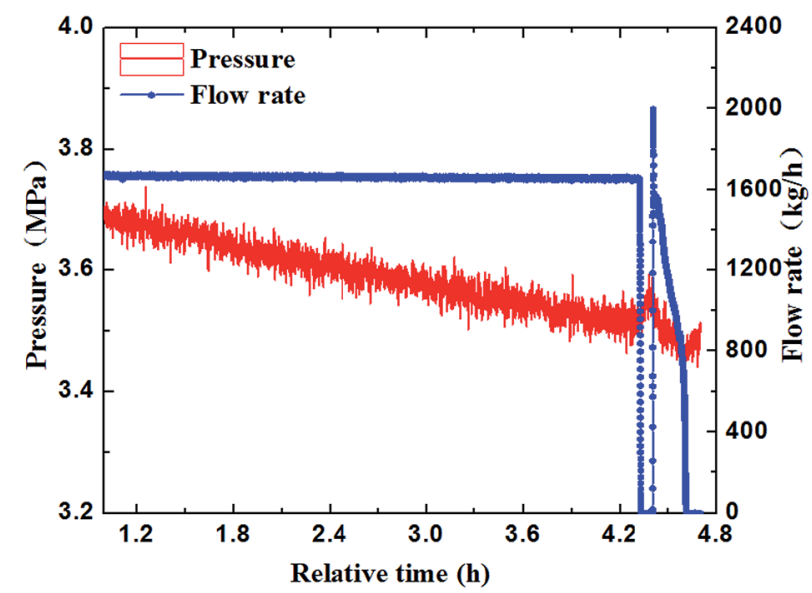

Fig. 8 Flow rate as a function of relative time $\left(30 \mathrm{~Hz} / 1657 \mathrm{~kg} \mathrm{~h}^{-1}\right)$.

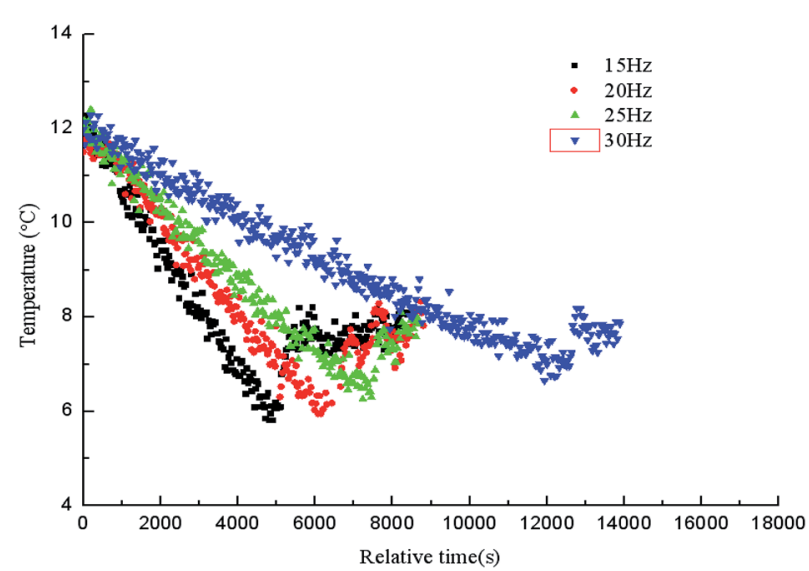

Fig. 9 Temperature as a function of relative time with different initial frequencies.

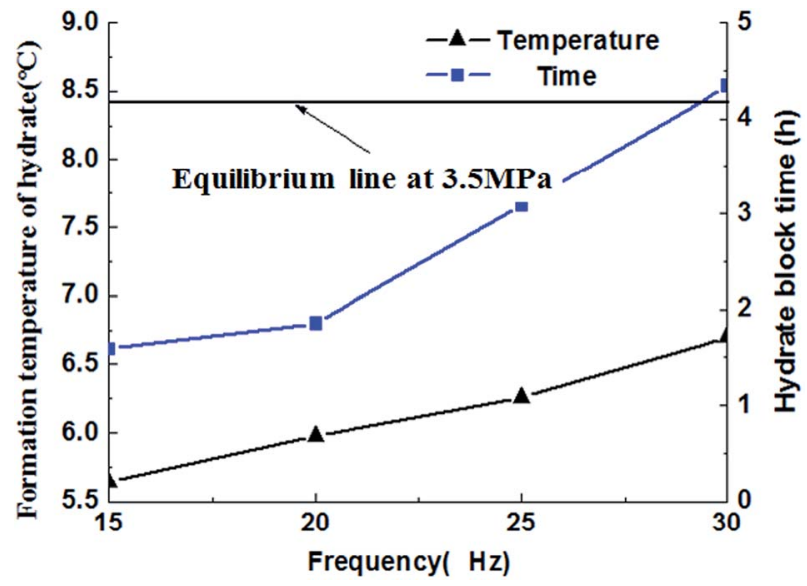

Fig. 10 Hydrate formation temperature and blockage time as the functions of relative time with different initial frequencies.

increase of flow rate. Besides, the plugging time increased remarkably when the flow rate increased. So, a proper high flow rate could extend the plugging time, reduce the possibility of the occurrence of plugging in pipeline operation. ${ }^{32}$

\subsection{The influence of pressure on the blockage of hydrate}

In order to further study the experiments of $\mathrm{CO}_{2}$ hydrate blockage under different pressure, a series of hydrate plugging experiments were carried out with $2.8 \mathrm{MPa}$ and 3.8 MPa. Fig. 10 showed that the temperature of the system went up due to the large amount of heat released by hydrate particles crystallization. So the temperature when hydrate began to form in large quantities was defined as $T_{\mathrm{b}}$, and the time that the hydrate blocked the pipe was defined as $T_{\mathrm{h}}$. As shown in Fig. 11, the $T_{\mathrm{b}}$ under high pressure was higher than the low pressure; the $T_{\mathrm{h}}$ under high pressure was about 1.7 hours, while it was about 2.4

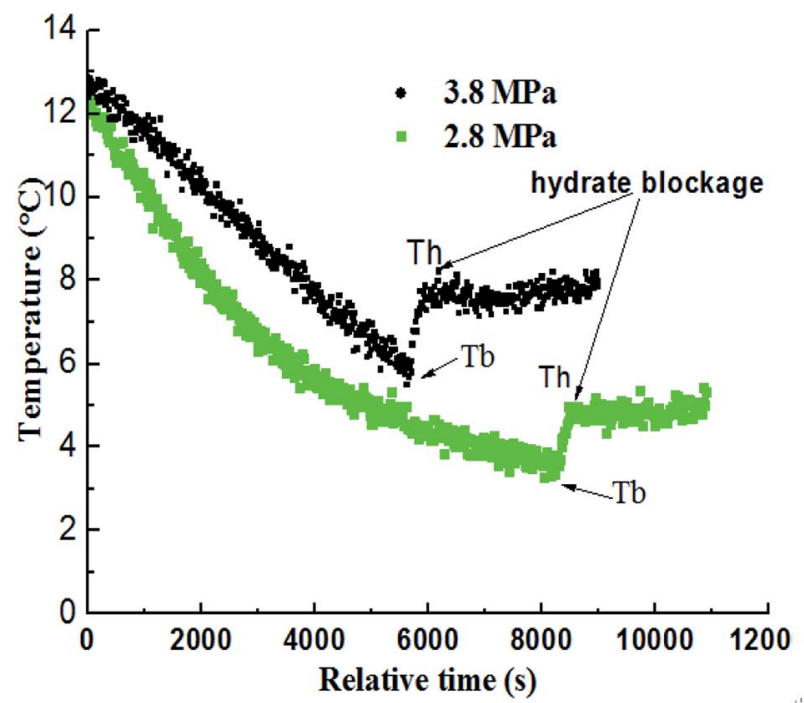

Fig. 11 Temperature as a function of relative time under different pressure $\left(15 \mathrm{~Hz} / 754 \mathrm{~kg} \mathrm{~h}^{-1}\right)$. 
Table 1 The comparison of $T_{\mathrm{b}}$ and $T_{\mathrm{h}}$ at different pressure

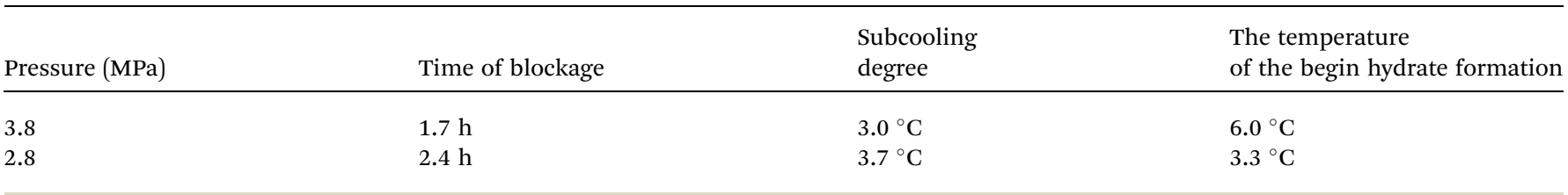

hours under the low pressure. Obviously, the blockage time under high pressure was less than the low pressure, and the supercooling degree needed for the hydrate formation was also lower under high pressure. ${ }^{27}$ The value of $T_{\mathrm{b}}$ and $T_{\mathrm{h}}$ under different pressure was shown in Table 1 . It could be concluded that the needed supercooling degree decreased with the pressure increased under the same flow rate, so the hydrate was easier to form, and there was a relatively short hydrate blockage time. Therefore, the factor of pressure had a remarkable influence on the hydrate formation and the blockage of the pipe. $^{28,31-34}$

\subsection{The micro characteristic during the $\mathrm{CO}_{2}$ hydrate formation}

3.4.1 The distribution of $\mathrm{CO}_{2}$ hydrate particle chord length. Fig. 12-14 represented the distribution of particle chord length before and in the process of $\mathrm{CO}_{2}$ hydrate formation under different flow rates. From the three figures, it was known that under the different flow rate, the distribution of particle chord length followed certain regularities before and after the hydrate formation. Namely along with the formation of $\mathrm{CO}_{2}$ hydrates, the distribution of particle chord length moved to the right side where the large particles locate, representing the trend that the number of large particles in the system increased after hydrate formation. ${ }^{29}$

For the further explanation of the phenomenon that under the different flow rates, the number of large particles in the system increased after hydrate formation, a method of square

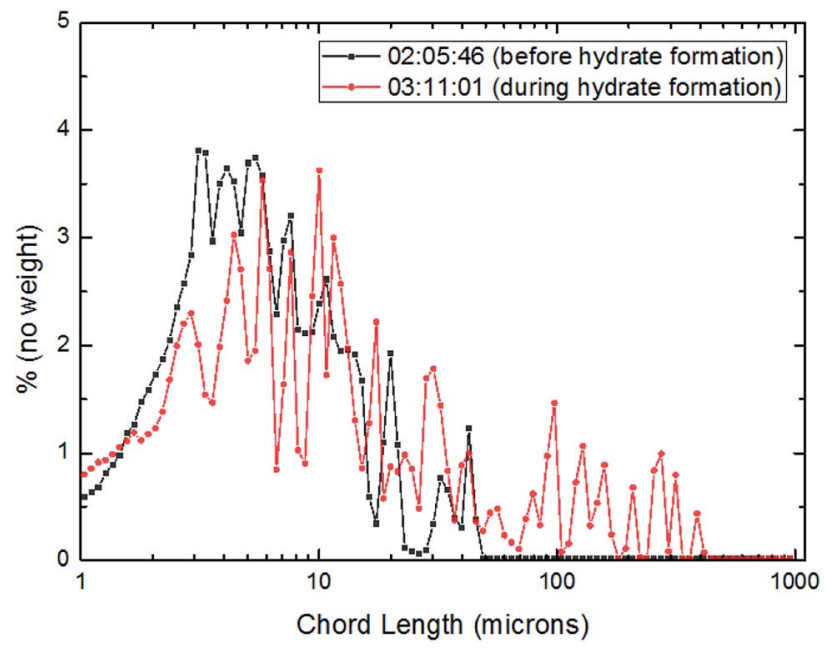

Fig. 12 Distribution of particles/droplets chord length before and after $\mathrm{CO}_{2}$ hydrate formation $\left(10 \mathrm{~Hz} / 450 \mathrm{~kg} \mathrm{~h}^{-1}\right.$ ). weighted particle chord length was introduced here in order to significantly characterize the changing trend of large particle chord length after hydrate formation. ${ }^{36}$ The details were shown as Fig. 15-17.

From Fig. 15-17, it could be seen that the distribution of large particle chord length have changed significantly after $\mathrm{CO}_{2}$ hydrate formation. The distribution of large particle chord length concentrated in the range from 10 to100 microns before $\mathrm{CO}_{2}$ hydrate formation, while it was mainly in the range from

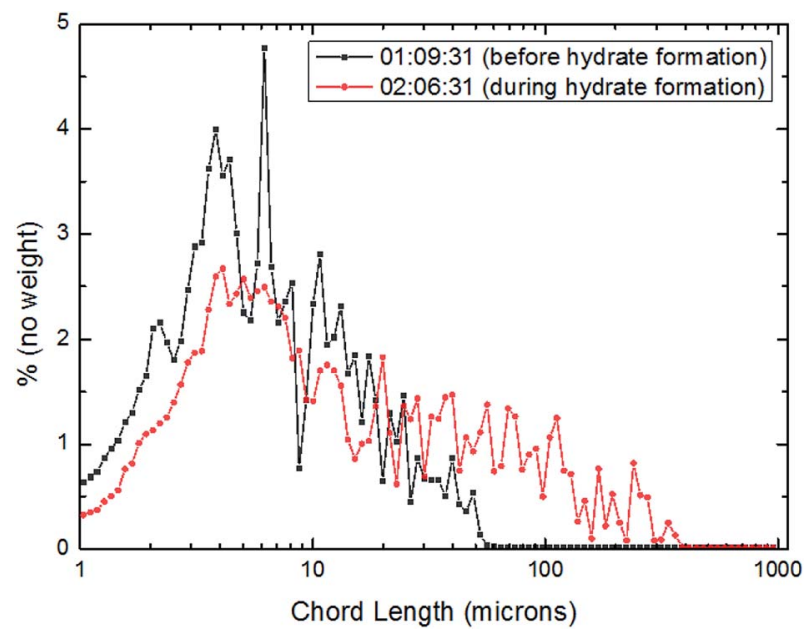

Fig. 13 Distribution of particles/droplets chord length before and after $\mathrm{CO}_{2}$ hydrate formation $\left(15 \mathrm{~Hz} / 754 \mathrm{~kg} \mathrm{~h}^{-1}\right)$.

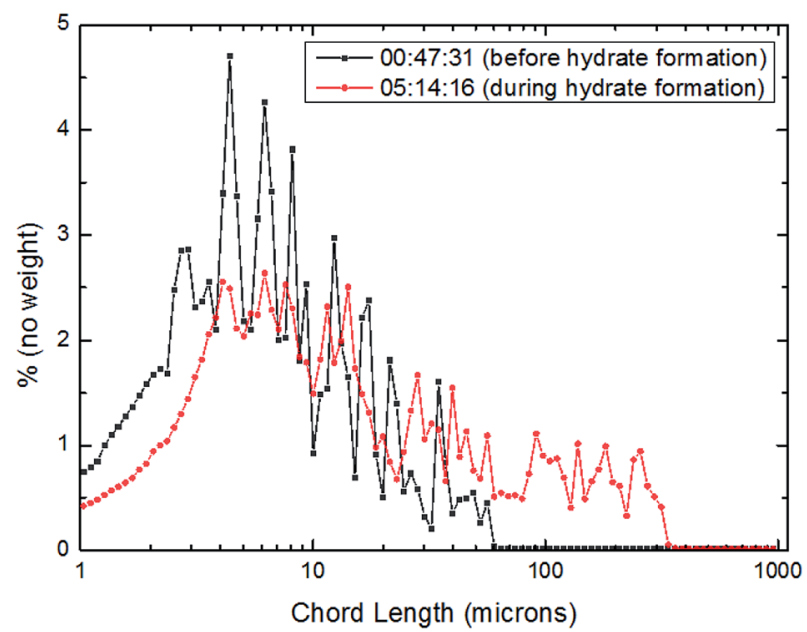

Fig. 14 Distribution of particles/droplets chord length before and after $\mathrm{CO}_{2}$ hydrate formation $\left(20 \mathrm{~Hz} / 1041 \mathrm{~kg} \mathrm{~h}^{-1}\right)$. 
100 to 400 microns after $\mathrm{CO}_{2}$ hydrate formation. That is, the distribution of large particle chord length moved to the right side obviously after $\mathrm{CO}_{2}$ hydrate formation. This trend has been confirmed by some researchers. ${ }^{23,29,31-36}$

3.4.2 The distribution of the average and square weighted particle chord length. In order to better understand the particle chord length at different time during the $\mathrm{CO}_{2}$ hydrate formation, we specially studied the average particle chord length and square weighted particle chord length in this process, as shown in Fig. 18-20.

It could be concluded from Fig. 18-20 that throughout the entire process of $\mathrm{CO}_{2}$ formation, both the average particle chord length and square weighted particle chord length have experienced a vibrated period with initial dissolved gas, a stable stage before formation and a fluctuated period with large particles' breakage after the formation.

Average particle chord length of this system remained essentially between 9-10 microns in the stable stage before

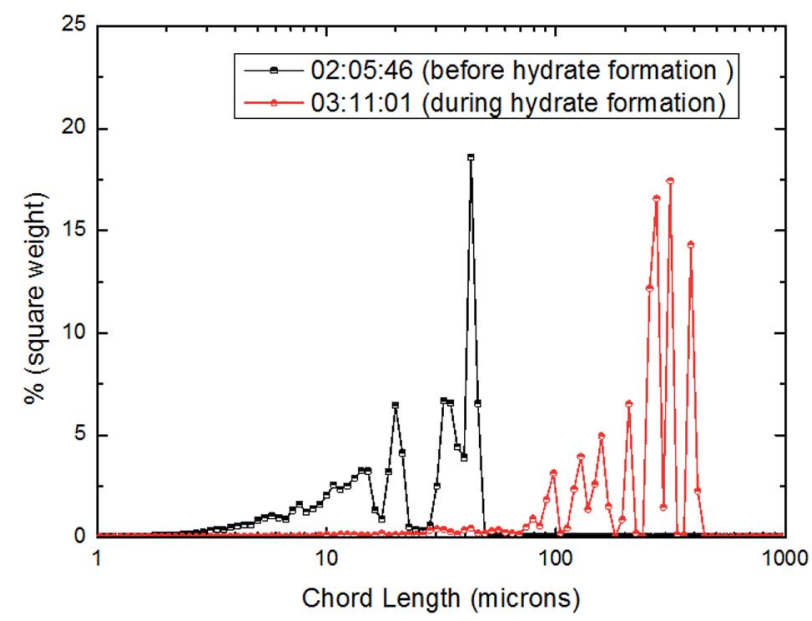

Fig. 15 Distribution of square weighted particles/droplets chord length before and after $\mathrm{CO}_{2}$ hydrate formation $\left(10 \mathrm{~Hz} / 450 \mathrm{~kg} \mathrm{~h}^{-1}\right)$.

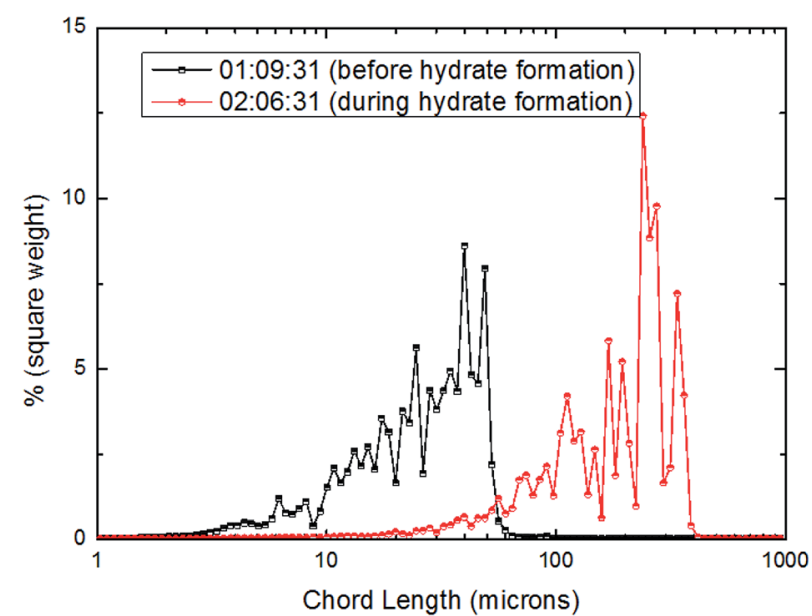

Fig. 16 Distribution of square weighted particles/droplets chord length before and after $\mathrm{CO}_{2}$ hydrate formation $\left(15 \mathrm{~Hz} / 754 \mathrm{~kg} \mathrm{~h}^{-1}\right)$.

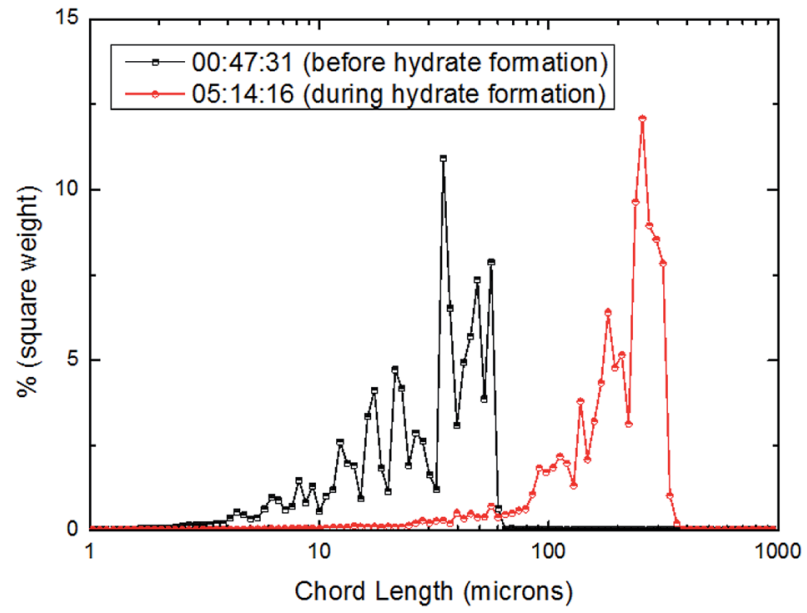

Fig. 17 Distribution of square weighted particles/droplets chord length before and after $\mathrm{CO}_{2}$ hydrate formation $\left(20 \mathrm{~Hz} / 1041 \mathrm{~kg} \mathrm{~h}^{-1}\right)$.

hydrate formation, when square weighted particle chord length was basically between 25-35 microns. While after the $\mathrm{CO}_{2}$ formation, average particle chord length vibrated between 15-
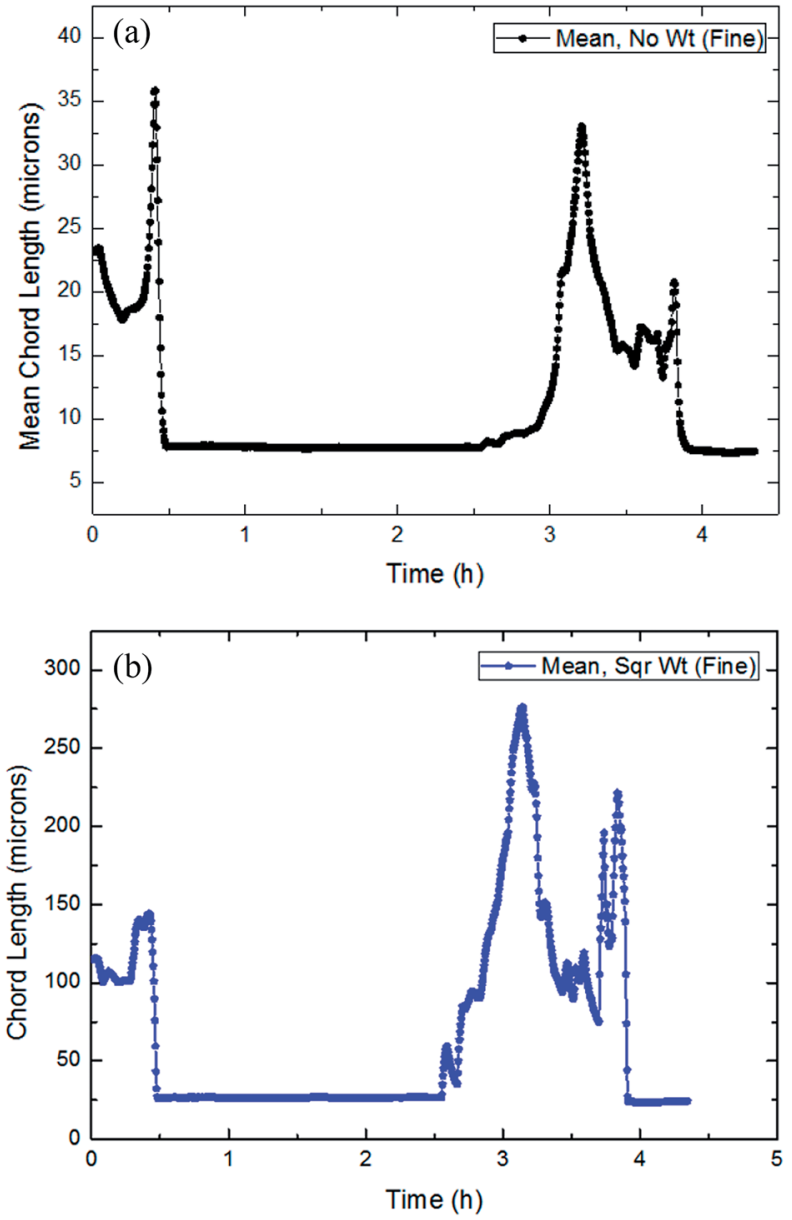

Fig. 18 The trend of the average and square weighted particles/ droplets chord length distribution with time in flow rate $(10 \mathrm{~Hz} / 450 \mathrm{~kg}$ $\mathrm{h}^{-1}$ : $\mathrm{a}$ and $\left.\mathrm{b}\right)$. 

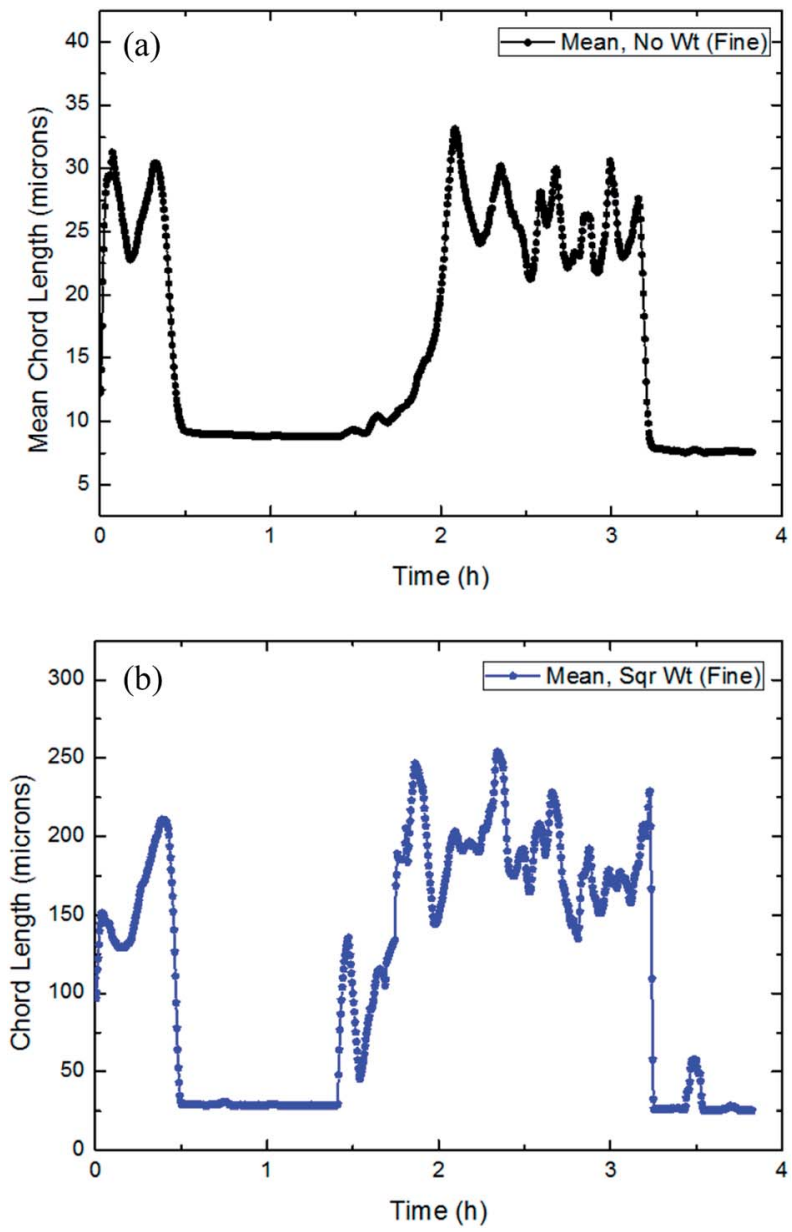

Fig. 19 The trend of the average and square weighted particles/ droplets chord length distribution with time in flow rate $(15 \mathrm{~Hz} / 754 \mathrm{~kg}$ $\mathrm{h}^{-1}$ : $\mathrm{a}$ and $\mathrm{b}$ ).

40 microns, when square weighted particle chord length changed between 150-300 microns.

During the $\mathrm{CO}_{2}$ hydrate formation, both average particle chord length and square weighted particle chord length changed significantly, which powerfully proved the existence of the phenomena that the particles collided and coalesced at the same time. ${ }^{30}$ And according to the variations of the average particle chord length and square weighted particle chord length, it was possible to predict the strength of the particle collision and coalescence, then to quantify the risk of pipeline hydrate plug. ${ }^{35}$ At the same time, it also could be seen that the square weighted particle chord length had earlier as well as greater changes than the average particle chord length. It proved that square weighted particle chord length was more sensitive to the collision and coalescence of particles. ${ }^{33,36}$

The fluctuated period after hydrate formation reflected that the large particles experienced breakage and coalescence at the same time under the shear effect, which was a dynamic equilibrium process, as shown in Fig. 21.

Fig. 21 showed that the share of large particles increased notably at the beginning of hydrate formation period,
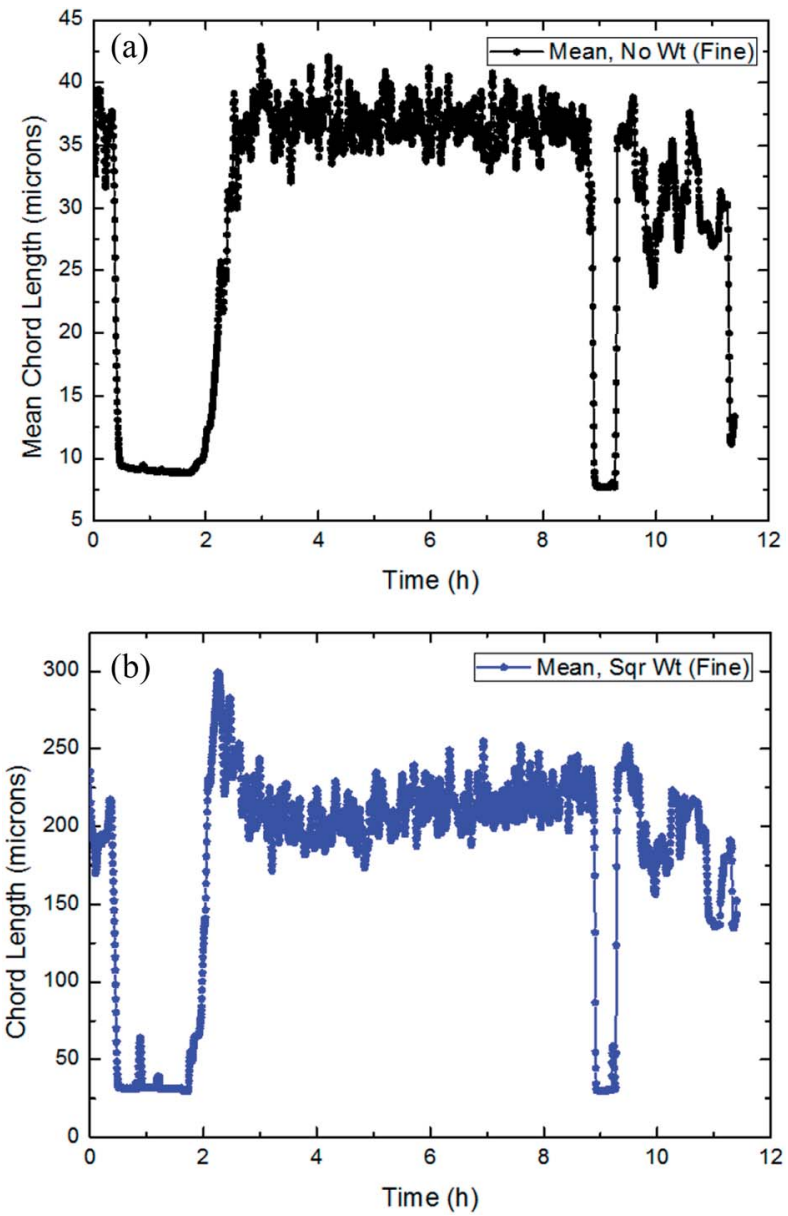

Fig. 20 The trend of the average and square weighted particles/ droplets chord length distribution with time in flow rate $(20 \mathrm{~Hz} / 1041 \mathrm{~kg}$ $\mathrm{h}^{-1}$ : $\mathrm{a}$ and $\left.\mathrm{b}\right)$.

indicating the coalescence of hydrate particles. When it arrived at stable phase, the accumulated percentage curve of particle chord length moved left, implying reduced number of large particles. This was due to the larger particles were broken under the shear effect. Despite of less large particles, the accumulated percentage curve of particle chord length was still on the right side of the curve which was produced before hydrate formation.

3.4.3 The trend of total number of particles/droplets during the process of $\mathrm{CO}_{2}$ hydrate formation. From the mentioned above, it could be known that particles in the system would collide and coalescence, inevitably leading to the change of particle number during the $\mathrm{CO}_{2}$ hydrate formation. On this basis, this paper had carried on the statistics. The experimental results were shown in Fig. 22-24.

It could be seen in Fig. 22-24 that the number of particles/ droplets in the system was roughly between $21000-24000$ in the stable stage before hydrate formation; while it reduced significantly in the process of hydrate formation to about 10 000-12 000. Moreover the number of particles/droplets in the system vibrated markedly after the hydrate formation due 


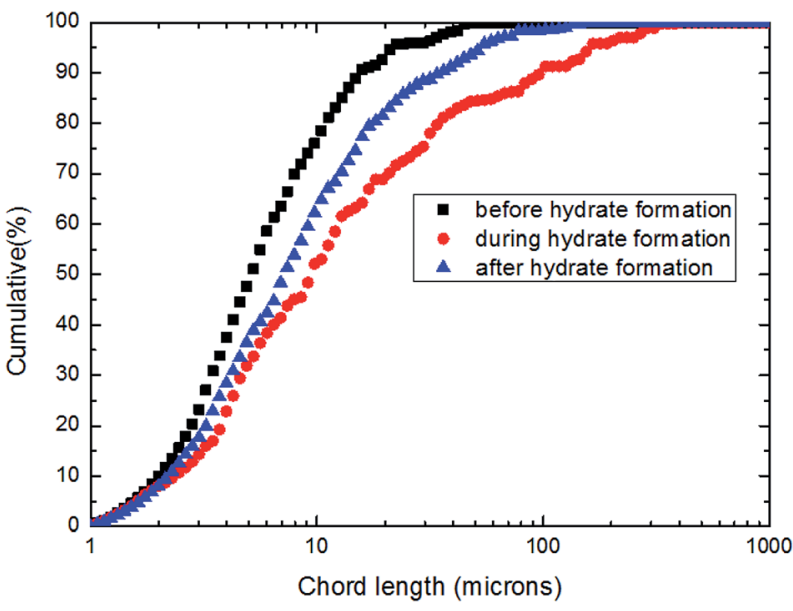

Fig. 21 The cumulative particles/droplets chord length distribution before and during $\mathrm{CO}_{2}$ hydrate formation $\left(10 \mathrm{~Hz} / 450 \mathrm{~kg} \mathrm{~h}^{-1}\right)$.

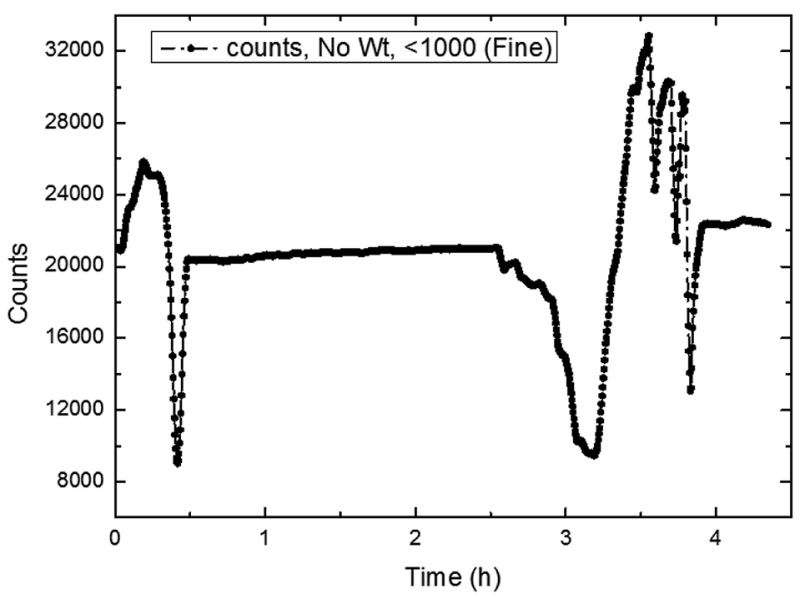

Fig. 22 The trend of total number of particles/droplets during the process of $\mathrm{CO}_{2}$ hydrate formation $\left(10 \mathrm{~Hz} / 450 \mathrm{~kg} \mathrm{~h}^{-1}\right)$.

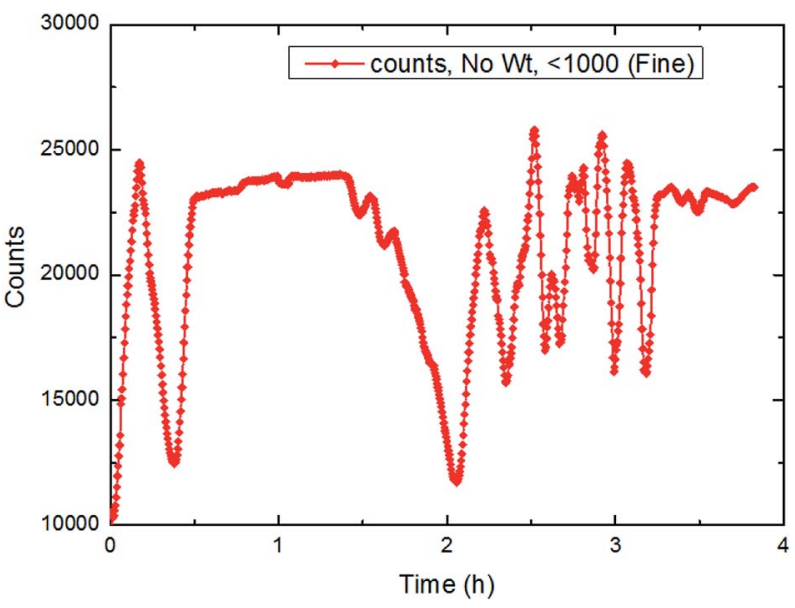

Fig. 23 The trend of total number of particles/droplets during the process of $\mathrm{CO}_{2}$ hydrate formation $\left(15 \mathrm{~Hz} / 754 \mathrm{~kg} \mathrm{~h}^{-1}\right)$.

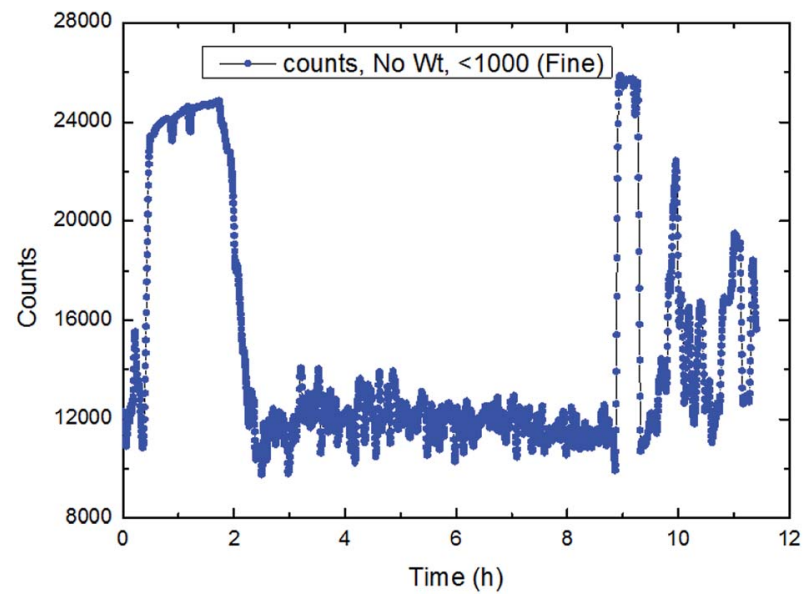

Fig. 24 The trend of total number of particles/droplets during the process of $\mathrm{CO}_{2}$ hydrate formation $\left(20 \mathrm{~Hz} / 1041 \mathrm{~kg} \mathrm{~h}^{-1}\right)$.

to large particles was broken under the shear effect. Therefore, we could monitor the total number of particles at all times during the experiments so as to predict and characterize the hydrate formation process.

\section{Conclusions}

(1) The $\mathrm{CO}_{2}$ hydrates might generate somewhere at the pipe wall and then they gather together and finally block the pipe. Once a blockage happened, restarting of the pump was not only of no sense, but also might make this problem more serious.

(2) Under the same pressure condition, faster flow rate could weaken the driving force of hydrate formation, increase the starting temperature of blockage and lengthen the duration of the first plugging. Increasing velocity could promote the shear of fluid to the pipe wall, but this effect was not very obvious during the plugging and gathering process. With the increase of the flow rate, the inducing time of hydrate formation would prolong, and the influence of shear on nucleation would be more obvious.

(3) Also, the dimensions of particles in the fluid have been changing throughout the hydrate formation process. It might be inferred that the occurrence of hydrate blockage was time dependent, and its relative time was affected by pressure as well as flow rate in the system.

\section{Conflicts of interest}

There are no conflicts to be declare.

\section{Acknowledgements}

This work was supported by the National Science Foundation for Young Scientists of China (Grant No. 51804046), PetroChina Innovation Foundation (Grant No. 2018D-5007-0602) and Natural Science Research Project of Jiangsu Colleges and Universities (Grant No. 18KJB440001). 


\section{References}

1 Z. W. Ma, P. Zhang, H. S. Bao and S. Deng, Review of fundamental properties of $\mathrm{CO}_{2}$ hydrates and $\mathrm{CO}_{2}$ capture and separation using hydration method, Renewable Sustainable Energy Rev., 2016, 53, 1273-1302.

2 J. Oignet, A. Delahaye, J. Torre, et al., Rheological study of $\mathrm{CO}_{2}$ hydrate slurry in the presence of Sodium Dodecyl Sulfate in a secondary refrigeration loop, Chem. Eng. Sci., 2017, 158, 294-303.

3 M. Bai, Z. Zhang and X. Fu, A review on well integrity issues for $\mathrm{CO}_{2}$ geological storage and enhanced gas recovery, Renewable Sustainable Energy Rev., 2016, 59, 920-926.

4 L. Li, N. Zhao, W. Wei, et al., A review of research progress on $\mathrm{CO}_{2}$ capture, storage, and utilization in Chinese Academy of Sciences, Fuel, 2013, 108, 112-130.

5 D. Zhong, Z. Li, Y. Lu, et al., Investigation of $\mathrm{CO}_{2}$ Capture from a $\mathrm{CO}_{2}+\mathrm{CH}_{4}$ Gas Mixture by Gas Hydrate Formation in the Fixed Bed of a Molecular Sieve, Ind. Eng. Chem. Res., 2016, 55(29), 7973-7980.

6 P. Babu, R. Kumar and P. Linga, Pre-combustion capture of carbon dioxide in a fixed bed reactor using the clathrate hydrate process, Energy, 2013, 50, 364-373.

7 H. Dashti, L. Zhehao and X. Lou, Recent advances in gas hydrate-based $\mathrm{CO}_{2}$ capture, J. Nat. Gas Sci. Eng., 2015, 23, 195-207.

8 B. Castellani, M. Filipponi, A. Nicolini, et al., Carbon Dioxide Capture Using Gas Hydrate Technology, J. Energy Power Eng., 2013, 7, 883-890.

9 N. H. Duc, F. Chauvy and J. M. Herri, $\mathrm{CO}_{2}$ capture by hydrate crystallization-A potential solution for gas emission of steelmaking industry, Energy Convers. Manage., 2007, 48, 1313-1322.

10 S. Tomita, S. Akatsu and R. Ohmura, Experiments and thermodynamic simulations for continuous separation of $\mathrm{CO}_{2}$ from $\mathrm{CH}_{4}+\mathrm{CO}_{2}$ gas mixture utilizing hydrate formation, Appl. Energy, 2015, 146, 104-110.

11 A. Eslamimanesh, A. H. Mohammadi, D. Richon, et al., Application of gas hydrate formation in separation processes: A review of experimental studies, The Journal of Chemical Thermodynamics, 2012, 46, 62-71.

12 P. Babu, P. Linga, R. Kumar, et al., A review of the hydrate based gas separation (HBGS) process for carbon dioxide pre-combustion capture, Energy, 2015, 85, 261-279.

13 C. $\mathrm{Xu}, \mathrm{Z}$. Y. Chen, J. Cai, et al., Study on Pilot-Scale $\mathrm{CO}_{2}$ Separation from Flue Gas by the Hydrate Method, Energy Fuels, 2014, 28, 1242-1248.

14 X. S. Li, Z. M. Xia, Z. Y. Chen, et al., Gas Hydrate Formation Process for Capture of Carbon Dioxide from Fuel Gas Mixture, Ind. Eng. Chem. Res., 2010, 49, 11614-11619.

15 Z. M. Xia, X. S. Li, Z. Y. Chen, et al., Hydrate-based Capture $\mathrm{CO}_{2}$ and Purification $\mathrm{CH}_{4}$ from Simulated Landfill Gas with Synergic Additives Based on Gas Solvent, Energy Procedia, 2014, 61, 450-454.
16 F. Qanbari, M. Pooladi-Darvish and S. H. Tabatabaie, $\mathrm{CO}_{2}$ disposal as hydrate in ocean sediments, J. Nat. Gas Sci. Eng., 2012, 8(8), 139-149.

17 A. C. Chow, E. E. Adams, P. H. Israelsson, et al., Carbon dioxide hydrate particles for ocean carbon sequestration, Energy Procedia, 2009, 1, 4937-4944.

18 S. Jerbi, A. Delahaye, J. Oignet, et al., Rheological properties of $\mathrm{CO}_{2}$ hydrate slurry produced in a stirred tank reactor and a secondary refrigeration loop, Int. J. Refrig., 2013, 36, 12941301.

19 J. Guilpart, E. Stamatiou, A. Delahaye, et al., Comparison of the performance of different ice slurry types depending on the application temperature, Int. J. Refrig., 2006, 29, 781-788.

20 L. Fournaison, A. Delahaye, I. Chatti, et al., $\mathrm{CO}_{2}$ hydrates in refrigeration processes, Ind. Eng. Chem. Res., 2004, 43, 65216526.

21 P. Zhang and Z. W Ma, An overview of fundamental studies and applications of phase change material slurries to secondary loop refrigeration and air conditioning systems, Renewable Sustainable Energy Rev., 2012, 16, 5021-5058.

22 Z. Youssef, A. Delahaye, L. Huang, et al., State of the art on phase change material slurries, Energy Convers. Manage., 2013, 65, 120-132.

23 A. Delahaye, L. Fournaison, S. Marinhas, et al., Rheological study of $\mathrm{CO}_{2}$ hydrate slurry in a dynamic loop applied to secondary refrigeration, Chem. Eng. Sci., 2008, 63, 35513559.

24 A. Delahaye, L. Fournaison, S. Jerbi, et al., Rheological properties of $\mathrm{CO}_{2}$ hydrate slurry flow in the presence of additives, Ind. Eng. Chem. Res., 2011, 50, 8344-8353.

25 S. Jerbi, A. Delahaye, J. Oignet, et al., Rheological properties of $\mathrm{CO}_{2}$ hydrate slurry produced in a stirred tank reactor and a secondary refrigeration loop, Int. J. Refrig., 2013, 36, 12941301.

26 A. K. Sum, D. T. Wu and K. Yasuoka, Energy science of clathrate hydrates: simulation based advances, MRS Bull., 2011, 36, 205-210.

27 E. D. Sloan and C. A. Koh, Clathrate hydrates of natural gases, 3rd edn, CRC Press, New York, 2008.

28 E. D. Sloan, C. A. Koh and A. K. Sum, et al., Natural Gas Hydrates in Flow Assurance, Elsevier, Amsterdam, Boston, Heidelberg, London, New York, Oxford, Paris, San Diego, San Francisco, Singapore, Sydney, Tokyo, 2010.

29 J. Chen, K. L. Yan, G. J Chen, et al., Insights into the formation mechanism of hydrate plugging in pipelines, Chem. Eng. Sci., 2015, 122, 284-290.

30 J. W. Nicholas, L. E. Dieker, E. D. Sloan, et al., Assessing the feasibility of hydrate deposition on pipeline walls-Adhesion force measurements of clathrate hydrate particles on carbon steel, J. Colloid Interface Sci., 2009, 331(2), 322-328.

31 J. W. Lachance, L. D. Talley, D. P. Shatto, et al., Formation of Hydrate Slurries in a Once-Through Operation, Energy Fuels, 2012, 26(7), 4059-4066.

32 Y. H. Sohn, J. Kim, K. Shin, et al., Hydrate plug formation risk with varying watercut and inhibitor concentrations, Chem. Eng. Sci., 2015, 126, 711-718. 
33 X. Lv, B. Shi, Y. Wang, et al., Study on Gas Hydrate Formation and Hydrate Slurry Flow in a Multiphase Transportation System, Energy Fuels, 2013, 27(12), 7294-7302.

34 L. Ding, B. Shi, X. Lv, et al., Investigation of natural gas hydrate slurry flow properties and flow patterns using a high pressure flow loop, Chem. Eng. Sci., 2016, 146, 199206.
35 W. Li, J. Gong, X. Lü, et al., A study of hydrate plug formation in a subsea natural gas pipeline using a novel high-pressure flow loop, Pet. Sci., 2013, 10, 97-105.

36 B. Shi, L. Ding, W. Li, et al., Investigation on hydrates blockage and restart process mechanisms of $\mathrm{CO}_{2}$ hydrate slurry flow, Asia-Pac. J. Chem. Eng., 2018, 13, e2193. 